\title{
The authenticity, sterility, and stability of culturing human pluripotent stem cells
}

\author{
Hea-Jo Yoon and Woo Jung Ho* \\ Stem Cell Research Center, Apgujeong Miracle Clinic, South Korea
}

\section{Introduction}

Cultivation of human pluripotent stem cells (hPSCs) is necessary for experimental demand or clinical application. The culture of human stem cells shares many of the same standards as mammalian somatic cell culture. Since the cells in culture are exposed to a different environment from the environment of the living body, the cells per se tend to adapt and adapt to the culture conditions. Particularly, they can be easily affected by external pathogen or culture environment because hPSCs are dynamic cells with pluripotency and regeneration ability [1]. In addition, the method of maintaining undifferentiated state during longterm culture without loss of regeneration ability or pluripotency may affect the characteristics of cells resulting in changes of the authenticity, and instability of hPSCs. Qualitative assessments during the culture of hPSCs include purity, viability, morphological appearance, confluency (the percentage of the surface of a culture dish that is covered by adherent cells), functionality, contamination and cross-contamination, authenticity, differentiation state, and identification of genetic stability [1]. Among them, the key elements of cultivation of hPSCs would be authenticity, sterility, and stability of cell lines [1,2].

We had discussed about the contamination by bacteria and viruses, including mycoplasma, and the changes in the authenticity and stability of the cells that can occur during the culture period.

\section{Sterility}

Pathogens (e.g., bacteria, viruses, yeast and other fungi) can eradicate cells, and cause clinical risk. In addition to overt contaminations, slowly growing micro-organisms, or microorganisms resistant to antibiotics, can affect the cells invisibly, change the characteristics of cells and distort the experimental results $[1,3]$. It is crucial to maintain sterility in cell culture throughout the process of cell or tissue harvesting and throughout the culture. HPSCs are especially susceptible since they are commonly cultured in enriched media without antibiotics and antifungal agents [4]. Cultured cells should be checked for mycoplasma, bacteria, fungi, bovine viruses, porcine viruses, and human viral pathogens before banking or processing [5]. If the cell is contaminated, it should be discarded immediately, and it is better to discard the cells in the incubator that may be in contact. Removal of contamination without disposal of the cell line can be performed only if the cells in culture are not replaceable and, it should be handled under strict quarantine [4].

\section{Mycoplasma}

Mycoplasmas are the most common bacteria that cause culturing cell infections. These intracellular prokaryotic microorganisms are generally smaller than bacteria.

\section{Characteristics}

Resistance to antibiotics: Mycoplasma are resistant to common antibiotics including penicillin because they lack cell walls [2].

Penetration through sterilizing filtration: Mycoplasma may pass through standard filters $(>0.1 \mu \mathrm{m}$, usually $0.22 \mu \mathrm{m})$ especially at higher pressure rates [2].

Difficulty in the detection of infection: In addition, this organism can propagate without interfering with cell growth, making the culture cloudy, or causing no change in the $\mathrm{pH}$ of the culture medium [4].

\section{The impact on the cell}

The deleterious effects of mycoplasma include alteration of proliferation characteristics (growth, viability), alteration of cellular morphology, genetic instability, phenotypic changes, transformation, changes in physiological function, alteration of cellular metabolism, changes in cell membrane antigenicity (surface antigen and receptor expression), virus susceptibility (increase or decrease of virus propagation), cell death, cytopathic effects such as plaque formation, total culture degeneration, increased sensitivity to apoptosis, induction or inhibition of lymphocyte activation, induction or suppression of cytokine expression and interference with various biochemical assays $[2,4,6]$.

\section{Sources of infection}

The common sources of mycoplasma contamination are crosscontamination of cell lines from other mycoplasma-positive cell cultures, researchers, non-sterilizable reagents, laboratory equipment, the $\mathrm{N}_{2}$ liquid of cryopreservation vessels, and laboratory animals [2]. Contaminated culture reagents, new cell lines brought into the laboratory and laboratory workers are the main sources of $M$. orale, M. fermentans, and M. hominis contaminations. These sources account for more than half of mycoplasma contamination [4]. M. arginini can cause cell culture contamination through serum (fetal bovine serum, newborn bovine serum) [4].

\section{Test}

Although microbiological culture has been considered as a gold standard, alternative methods have been developed because

*Correspondence to: Woo Jung Ho, Stem Cell Research Center, Apgujeong Miracle Clinic, Seoul, South Korea, Tel: 82-1588-7013; Fax: 82-2000-7822; E-mail: miracleps77@naver.com

Received: March 01, 2019; Accepted: March 15, 2019; Published: March 25 2019 
the duration of microbiological culture is 28 days or longer [2]. Common methods used to detect mycoplasma include enzymatic assays, polymerase chain reaction (PCR), culture in selective media, and DNA staining of test cells to visualize mycoplasma. Commercial kits (including real-time PCR) can detect most of the mycoplasma with very high specificity and yields within two or three hours [2]. In the 2013 survey, only $25 \%$ of the laboratories conducted mycoplasma tests, and some of the scientific journal mandated completion of the mycoplasma test for publication [7].

\section{Change in infection rate}

$15 \%$ to $88.7 \%$ of cultured cells were reported to be infected with mycoplasma, and there was no noticeable decrease in infection rates after the initial discovery [2].

\section{Bacteria}

Changes of culture medium and detection: The infected culture medium is usually turbid and appears to be a sharp decrease in the $\mathrm{pH}$ of the culture medium. However, if the contamination is not severe, it may be impossible to judge the contamination by visual observation [4]. Under a low-resolution microscope, bacteria look like small granules that move between cells [4].

Sources of infection: Bacterial contamination can occur through water bath, fridges, sinks and researchers [2].

Prevention: The most effective method of preventing bacterial contamination is aseptic technology, the use of Class II biological safety cabinets (BSC II) and maintaining a clean cell culture laboratory environment [8]. The use of antibiotics in the culture medium may be necessary during derivation of cell lines. But is not recommended for routine use in cell banking or culture since it affects cellular physiology and leads to a false sense of safety [2].

\section{Virus}

Characteristics: Viruses are the most difficult contaminants to detect during cell culture due to their small size. The virus causes a change in the characteristics of the cultured cell. These include expression of viral sequences at the DNA and RNA level without producing infectious virus particles, utilization of host cellular resources for viral replication and integration into the genome of the cultured cells for viral replication [9].

Deleterious effects: Viruses can destroy cells or cause long-term sub-lethal infection without killing cells. Cultured cells contaminated with blood-borne viruses can cause serious physical risks. Bovine serum with bovine viral diarrhea virus (BVDV) causes contamination of cultured cells, which slows cell growth but is difficult to detect under microscope. Immunocompetent humans are not susceptible to BVDV. The common viral pathogens tested in cells culture are: hepatitis $C$ virus, human immunodeficiency virus, human T-lymphotropic virus I/ II, Epstein-Barr virus, human cytomegalovirus, human papillomavirus, herpes simplex virus, and human herpes viruses.

Sources of infection: Sources of viral contamination are cell lines, animal-derived culture reagents that cannot be sterilized (especially trypsin and serum), antibodies, primary cultures (such a mouse embryonic fibroblasts) and the operator $[10,11]$.

\section{Cell line authenticity}

Cell lines that you plan to cultivate can turn into other cell lines by cross-contamination (the contamination of the cell culture of interest with other cell lines and replacing by misidentification or mislabeling. Checking of authenticity or identity of cell lines is a key component of minimum quality controls systems.

History: Problems of authenticity of cell lines which were associated with mislabeled, cross-contaminated and overgrown by other cells date back to the 1960s [3]. Many cell lines have been found to be switched or cross-contaminated into HeLa cells without the researchers knowing [11]. It could take decades to resolve any ongoing issues from published work on misidentified or contaminated lines alone [12].

Background and results: There are strong demands on researchers to generate multiple hPSCs lines simultaneously. Cellular crosscontamination, misidentified cell lines, and the use of high-passage culturing cells can lead to the experimental or clinical misleading results [13].

Incidence: In general, $18-36 \%$ of all cell lines were demonstrated to be wrongly identified [13]. Studies have shown that up to $30 \%$ of cell lines donated to public repositories are contaminated by cell types that proliferate rapidly beyond the original cell line, such as HeLa cells [11]. According to a study by Whitesides et al. [14] 9\% of survey respondents were using HeLa contaminants without their knowledge, but this figure may also be underestimated because only one-third of respondents tested for cell identity. Nonetheless, Shannon et al. [7] reported that only $46 \%$ of the researchers tested the authenticity of the cell line.

Timing of authentication: Authentication of cell lines is required when cross-contamination of the cell is suspected, at least before the cell line obtained from the outside is used in the experiment [4].

Methods: Identification of cell lines can be achieved by comparing the unique characteristics of received cell lines with those of the original isolate. Many test methods have been proposed: chromosomal analysis/karyotyping, isoenzyme analysis, multilocus DNA fingerprint analysis, short tandem repeat (STR) profiling, polymerase chain reaction fragment analysis and sequencing of "DNA barcode"regions [2]. Genotyping can differentiate small genetic variations in each cell lines [2]. DNA typing utilizes PCR-based techniques to analyze similar highly polymorphic DNA sequences via DNA fingerprinting analysis [15]. The International Stem Cell Banking Initiative (ISCBI) recommends using the core 13 loci for stem cell identification without providing specifics on the number of loci to be used [1]. Currently, the Short Tandem Repeats (STR) profiling is the reference method for cell line identification [2].

\section{Cell line stability}

Cell line stability means maintaining the original cell characteristics during cell culture. Because of selective pressures and genetic drift, if the cell lines are cultured for a long time, their original functions may change or disappear, resulting in different characteristics from the original cells [13]. In addition, iPSCs can spontaneously differentiate (partially or completely) during their propagation, favoring such heterogeneity.

Causes of instability: The causes of karyotypic instability could include long-term culture, stress during passaging, and the nature of the original hPSCs (genotypic or epigenetic variations) [4]. Genotypic or epigenetic variations in hPSCs can stem from variations inherent to the donor cells, changes induced in the reprogramming process, or accumulation during culture passaging. The epigenetic memory of the cell can be said to be the set of modifications to DNA without changing the DNA sequence and inherited modification could alter 
gene expression resulting in change of the properties and behavior of the cell [13]. In addition, the genetic mutation in the cell sometimes promotes the growth of the cell and can change into an abnormal cell. There is evidence suggesting that changes in the genetic machinery may confer a growth advantage of the aberrant population, producing a selective advantage to those cells and affecting cell population homogeneity [16].

It is important to maintain stem cells in an undifferentiated state if the undifferentiated stem cells are to be used for regenerative therapy [6]. However, stem cell karyotypic aberrations can be induced to maintain the cells in a stable state over a long passage, which increases the likelihood of malignant transformation at the same time as progressive adaptation of self-renewing cells to their culture conditions [6]. Genetic manipulation can alter characteristics of hPSCs. Characterization of the cells must be done before and after genetic manipulation in order to identify any deleterious changes that may have occurred [4].

Test: The ISCBI guideline recommended G-banding of cells for cell banking for identification of cell line stability [5,17]. Higher resolution genomic methods including comparative genome hybridization (CGH) microarrays, single nucleotide polymorphism (SNP) arrays and whole genome sequencing could be utilized [18]. However, these higher resolution genomic methods provide a lot of data but has limitations because it is difficult to know how the analyzed information specifically affects cell stability [19]. Although the in vivo teratoma assay has been accepted as a gold standard to confirm pluripotency of hPSCs, it can be replaced by an in vitro embryoid body (EB) assay due to lack of definitive clinical significance, the lack of reliability across methodologies, and high expenses [20]. It is recommended that the genetic stability of cell lines every 5-10 passages be checked. The PSC cultured to treat the patient should be carefully examined for mutation and for karyotypic changes to could predispose tumor formation.

\section{References}

1. Pamies D, Bal-Price A, Simeonov A, Tagle D, Allen D, et al. (2017) Good cell culture practice for stem cells and stem-cell-derived models ALTEX 34: 95-132. [Crossref]

2. Corral-Vázquez C, Aguilar-Quesada R, Catalina P, Lucena-Aguilar G, Ligero G, et al. (2017) Cell lines authentication and mycoplasma detection as minimun quality control of cell lines in biobanking. Cell Tissue Bank 18: 271-280. [Crossref]

3. Crook JM, Hei D, Stacey G (2010) The international stem cell banking initiative (ISCBI): raising standards to bank on. In Vitro Cell Dev Biol Anim 46: 169-172. [Crossref]
4. Pamies D, Bal-Price A, Simeonov A, Tagle D, Allen D, et al. (2017) Good Cell Culture Practice for stem cells and stem-cell-derived models. ALTEX 34: 95-132. [Crossref]

5. Bickmore WA (2001) Karyotype analysis and chromosome banding. Els 1:1-6.

6. Lincoln CK, Gabridge MG (1998) Cell culture contamination: sources, consequences, prevention, and elimination. Methods Cell Biol 57: 49-65. [Crossref]

7. Shannon M, Capes-Davis A, Eggington E, Georghiou R, Huschtscha LI, et al. (2016) Is cell culture a risky business? Risk analysis based on scientist survey data. Int J Cancer 138: 664-670. [Crossref]

8. Caputo JL (1988) Biosafety procedures in cell culture. J Tissue Cult Methods 11: 223 227

9. Coecke S, Balls M, Bowe G, Davis J, Gstraunthaler G, et al. (2005) Guidance on good cell culture practice. a report of the second ECVAM task force on good cell culture practice. Altern Lab Anim 33: 261-287. [Crossref]

10. Stacey GN, Cobo F, Nieto A, Talavera P, Healy L, et al. (2006) The development of 'feeder'cells for the preparation of clinical grade hES cell lines: challenges and solutions. J Biotechnol 125: 583-588. [Crossref]

11. Nelson-Rees WA, Daniels DW, Flandermeyer RR (1981) Cross-contamination of cells in culture. Science 212: 446-452. [Crossref]

12. Stacey GN, Crook JM, Hei D, Ludwig T (2013) Banking human induced pluripoten stem cells: lessons learned from embryonic stem cells? Cell Stem Cell 13: 385-388. [Crossref]

13. Vaskova EA, Stekleneva AE, Medvedev SP, Zakian SM (2013) "Epigenetic memory" phenomenon in induced pluripotent stem cells. Acta Naturae 5: 15-21. [Crossref]

14. Whitesides GM (2006) The origins and the future of microfluidics. Nature 442: 368373. [Crossref]

15. Dirks WG, Fähnrich S, Estella IA, Drexler HG (2005) Short tandem repeat DNA typing provides an international reference standard for authentication of human cell lines. ALTEX 22: 103-109. [Crossref]

16. Baker DE, Harrison NJ, Maltby E, Smith K, Moore HD, et al. (2007) Adaptation to culture of human embryonic stem cells and oncogenesis in vivo. Nat Biotechnol 25: 207-215. [Crossref]

17. Yu J, Vodyanik MA, Smuga-Otto K, Antosiewicz-Bourget J, Frane JL, et al. (2007) Induced pluripotent stem cell lines derived from human somatic cells. Science 318: 1917-1920. [Crossref]

18. Cheng L, Hansen NF, Zhao L, Du Y, Zou C, et al. (2012) Low incidence of DNA sequence variation in human induced pluripotent stem cells generated by nonintegrating plasmid expression. Cell Stem Cell 10: 337-44. [Crossref]

19. Kleensang A, Vantangoli MM, Odwin-DaCosta S, Andersen ME, Boekelheide K, et al. (2016) Genetic variability in a frozen batch of MCF-7 cells invisible in routine authentication affecting cell function. Scientific reports 6: 28994 .

20. Sheridan SD, Surampudi V, Rao RR (2012) Analysis of embryoid bodies derived from human induced pluripotent stem cells as a means to assess pluripotency. Stem Cells International 9: 738910-738919.

Copyright: (C2019 Yoon H. This is an open-access article distributed under the terms of the Creative Commons Attribution License, which permits unrestricted use, distribution, and reproduction in any medium, provided the original author and source are credited. 